\title{
El tercer hombre. Juan Baptista Piñero y los orígenes de la ruptura spinoziana
}

\author{
Markus Schreiber* \\ HistCom, Alemania
}

ORCID ID: https://orcid.org/0000-0002-3301-3241

A mediados del sigl XVII, en la comunidad sefardita de Ámsterdam se conocieron el joven Spinoza y el médico Juan de Prado. Israël S. Révah consideró el encuentro como el impulso inicial a una ruptura. Según el investigador francés, el cristiano nuevo Prado decisivamente influenció al futuro filósofo holandés y provocó el paso de este a la heterodoxia. Además, Révah en el criptojudaísmo ibérico vio los «orígenes de la ruptura spinoziana», tanto más cuanto que descubrió que estaba involucrado en el asunto un tercer hombre. Este Juan Piñero, que asimismo tenía un trasfondo judío, según un testimonio de la época a su vez empujó a Juan de Prado a la heterodoxia. Solo unas recientes investigaciones permiten la reconstrucción parcial de su vida extraordinaria, que refleja la crisis intelectual de ciertos círculos académicos en la España del siglo XVII.

Palabras clave: Juan Baptista Piñero; Juan de Prado; Spinoza; Salamanca; Sevilla; siglo XVII; medicina; criptojudaísmo; escepticismo; deísmo; spinozismo; Inquisición.

The Third Man. Juan Baptista Piñero and the Origins of the Spinozistic RUPTURE.- In the middle of the 17th century, the young Spinoza and the physician Juan de Prado met in the Sephardic community of Amsterdam. Israël S. Révah considered the encounter as the initial spark for a rupture. According to the French scholar, the New Christian Prado decisively influenced the future Dutch philosopher and provoked his shift to heterodoxy. Furthermore, Révah in Iberian Crypto-Judaism saw the origins of the Spinozistic rupture, the more as he discovered that there was a third man involved in the matter. This Juan Piñero, who also had a Jewish background, according to a testimony of the time on his part pushed Juan de Prado to heterodoxy. Only recent research allows the partial reconstruction of his extraordinary life, that reflects the intellectual crisis of certain academic circles in 17th-century Spain.

Keywords: Juan Baptista Piñero; Juan de Prado; Spinoza; Salamanca; Sevilla; 17th-century; Medicine; Crypto-Judaism; Scepticism; Deism; Spinozism; Inquisition.

\footnotetext{
*markus.schreiber@histcom.de
}

Copyright: (C) 2020 CSIC. Este es un artículo de acceso abierto distribuido bajo los términos de la licencia de uso y distribución Creative Commons Reconocimiento 4.0 Internacional (CC BY 4.0). 
Alrededor de 1653, una controversia científica sacudió al gremio de los médicos sevillanos. Entonces, los galenos de la metrópoli andaluza discutieron encarnizadamente en qué sitio del cuerpo humano había de aplicar la sangría. La historiografía moderna prácticamente no se ha interesado por aquel enfrentamiento. Sin embargo, una mirada atenta nos descubre que la disputa hispalense era más que una anécdota local del desarrollo científico hispánico. La discusión tocaba temas claves del arte médico premoderno e inició una controversia más amplia, que en Sevilla y otros sitios seguía hasta los años 80 del siglo XVII y contaba con un número alto de participantes. Entre ellos, encontramos a galenos destacados de la época al lado de figuras oscuras como Juan Baptista Piñero (1596-1662). Aquel hombre, sin embargo, en su momento tenía cierta fama y sus aportaciones a nuestra controversia médica son de las más interesantes. Y hay más. Podemos vincular a Piñero con el pensador más original y radical del siglo XVII.

Fue Israël S. Révah quien en una serie de trabajos pioneros reconstruyó la relación entre el joven Spinoza y el médico Juan de Prado ( $c a$. 1613-1669). Los dos heterodoxos coincidieron a mediados de los años 50 del siglo XVII en Ámsterdam, donde el doctor español con su ideario deísta empujaría al futuro filósofo holandés a la heterodoxia. Además, Révah llamó la atención sobre un enigmático tercer hombre, que según un testimonio de la época a su vez había «pervertido» a Prado y se llamaba Juan Piñero. Aquel fantasma realmente existía y era idéntico al homónimo que a mediados del siglo XVII participó en la controversia hispalense acerca de la sangría. Y podemos ofrecer más datos biográficos. Arrojan alguna luz sobre la vida de un personaje extraordinario, que tenía fama de ser el «corruptor» del «corruptor» de Spinoza.

\section{Música, PODER E INQUisición: Vila Viçosa}

El esplendor de la corte de los Duques de Braganza en Vila Viçosa (Alentejo) subrayaba el poder de la primera casa nobiliaria de Portugal. Y a esta brillantez contribuía su capilla musical, la más importante del reino y famosa dentro y fuera de las fronteras lusas. En 1576, fue nombrado un nuevo «mestre da capela» y este António Pinheiro ocuparía el importante puesto durante muchísimos años. El músico y compositor 
había nacido en 1553/1554 en Montemor-o-Novo y se crió en Évora, donde posiblemente en la catedral recibió una primera formación de cantor. Alrededor de 1566/1567, el mozo de doce años aproximadamente se pasó a Vila Viçosa para entrar en la capilla de los Duques de Braganza. Una década más tarde, el hombre joven ascendió de cantor a «mestre da capela» y a continuación despelegó una fecunda actividad de músico y compositor. Juan I, VI Duque de Braganza (ca. 1543-1583; gob. 1563-1583), y su hijo y sucesor Teodosio II, VII Duque de Braganza (1568-1630; gob. 1583-1630), debían de estar muy contentos con António Pinheiro, que hoy está reconocido como figura relevante de la cultura renacentista lusa. No obstante, en su larga carrera al servicio de la casa de Braganza hay una interrupción algo extraña, que los musicólogos explican con la actividad de nuestro compositor como «mestre da claustra» en la catedral de Évora. Sin embargo, es posible que la razón principal para la ausencia de Vila Viçosa fuese otra ${ }^{1}$.

En 1602, se produce el escándalo: António Pinheiro fue preso por el Santo Oficio. A partir de mayo del mismo año, el músico se encontraba en las cárceles secretas de la Inquisición de Évora. En su primera audiencia, el reo concedió que «tinha tres partes de Cristão nouo», pero la acusación de judaísmo la rechazó rotundamente. Tan graves las testificaciones no eran, sin embargo, venían del seno de la familia y el Santo Oficio en aquellos años procedía contra toda una serie de parientes de Pinheiro, entre ellos su madre y dos hermanas. Nuestro compositor, que en su favor podía alegar que estaba casado con una cristiana vieja, a continuación seguía con su estrategia defensiva y recalcaba que era un ejemplar cristiano. Aducía su actividad para la casa de Braganza y resaltaba la importancia de la música sacra para su trabajo como maestro de la capilla ducal. Y esto se reflejaba ante todo en sus propias composiciones:

${ }^{1}$ Proceso, António Pinheiro, Évora, 1596/1605/Arquivo NaCional DA Torre DO Томво, Lisboa, Tribunal do Santo Ofício, Inquisição de Évora, processo 8138, sin foliación; $c f$. Michael Ryan, «Pinheiro, António», en Oxford Music Online. Grove Music Online, ed. online en $2001<$ https://doi.org/10.1093/gmo/9781561592630.article.21780>; el artículo digital corresponde a la entrada en el tomo 19 de: The New Grove Dictionary of Music and Musicians, ed. Stanley SAdie (2a ed. London: MacMillan, 2001). 
«... no tempo $\mathrm{q}$ foi cantor da dita capella, e depois mestre della elle Reo fes e compos quatro, ou sinquo livros, dous delles de misas de canto de orgão, e hu de magnificas e psalmos, e dous de motetes e outras obras ao divino, os quais elle R. compos em serviço de nosso sor Jesu xpo...» ${ }^{2}$.

Para su defensa, António Pinheiro presentó una amplia lista de testigos. El duque y su familia, nombrados en primer lugar, no fueron interrogados. Aun el Santo Oficio debía guiarse por cierto grado de tino, tanto más cuanto que el hermano menor de Teodosio II, Alexandre de Bragança (1570-1608), era inquisidor general y arzobispo de Évora desde 1602. A los restantes testigos el vicario de Vila Viçosa sí les presentó el detallado cuestionario preparado por el reo y su procurador. Así, en 1603 toda una serie de cantores y músicos, de miembros de la corte ducal y de vecinos locales desfiló ante el encargado del Santo Oficio para constatar que el reo llevaba una vida impecable y era reconocido como cristiano viejo honrado. El mismo año, a petición de Pinheiro la Inquisición realizó unas investigaciones adicionales, que confirmaban la imagen. Luego no pasaba nada más y esto tenía que ver con las negociaciones simultáneas entre los cristianos nuevos portugueses, la corte en Valladolid y la curia romana acerca de un perdón general para los judaizantes lusos. Efectivamente, a principios de 1605 se promulgó el breve papal correspondiente y muchísimos reos de los tribunales inquisitoriales ibéricos fueron liberados. Entre ellos, se encontraron algunos familiares de António Pinheiro, el mismo salió de las cárceles secretas de Évora el 18 de enero de $1605^{3}$.

2 Proceso, António Pinheiro, Évora, 1596/1605/Arquivo Nacional Da Torre do Tомвo, Lisboa, Tribunal do Santo Ofício, Inquisição de Évora, processo 8138, sin foliación; en cuanto a los familiares de nuestro músico encausados por el Santo Oficio, solamente indicamos a su madre Jerónima Pinheira y sus hermanas Leonor Viegas y Ana Pinheira, que estaban presas en las cárceles secretas de la Inquisición de Évora alrededor de 1600. Aparte del proceso de Pinheiro, nos basamos en el banco de datos del ArQuivo Nacional da Torre do Tombo, Lisboa. Con las informaciones siguientes, las entradas se encuentran facilmente: Jerónima Pinheira (Inqu. de Évora, proc. 3396), Leonor Viegas (Inqu. de Évora, proc. 7644) y Ana Pinheira (Inqu. de Évora, proc. 7845).

3 Proceso, António Pinheiro, Évora, 1596/1605/Arquivo Nacional Da Torre DO Томво, Lisboa, Tribunal do Santo Ofício, Inquisição de Évora, processo 8138, sin foliación; además el banco de datos del Arquivo NaCional DA Torre Do Tombo, Lisboa: Leonor Viegas (Inqu. de Évora, proc. 7644), Jerónima Pinheira (Inqu. de Évora, 
Por razones comprensibles, el proceso comprometía la casa de Braganza y al mismísimo inquisidor general. Sin embargo, Teodosio II no retiró el apoyo a su «mestre de capela», a quien en 1605 incluso fue aumentado el sueldo y que el año siguiente recibió otro pago. No obstante, es posible que Pinheiro después de su puesta en libertad no volviese inmediatamente a Vila Viçosa y se quedase en Évora porque pronto servía de «mestre da claustra» en la catedral de la ciudad. El puesto, sin embargo, lo perdió ya en 1608, año en el que también murió el arzobispo eborense Alexandre de Bragança. Poco después, Pinheiro reanudó su actividad como director de la capilla ducal en Vila Viçosa, donde al parecer seguía como músico hasta 1616. El año siguiente, murió en Évora ${ }^{4}$.

António Pinheiro tenía sus raíces en la «nación» de los cristianos nuevos portugueses y no pocos parientes suyos a lo largo de más de 100 años fueron condenados como judaizantes. Ya en los años 60 del siglo XVI, su tío Mestre Marcos (ca. 1525-?), un cirujano, sufrió un proceso en la Inquisición de Évora, un siglo más tarde, Maria Cardosa (1620/1621-?), la hija de una sobrina del compositor, fue condenada por el mismo tribunal. A diferencia de numerosos familiares, António Pinheiro obviamente se despegaba paso a paso de su legado judío y tenía reputación de cristiano viejo, por lo menos hasta su proceso inquisitorial cuando su pasado acabó atrapándole. El encarcelamiento por el Santo Oficio remarcó el origen «oscuro» del maestro de capilla de los Duques de Braganza, con unas consecuencias más o menos sensibles para él y su familia 5 .

proc. 8058), Ana Viegas (Inqu. de Évora, proc. 2445) y João Viegas (Inqu. de Évora, proc. 6055).

${ }^{4}$ Cf. Ryan, «Pinheiro, António», y Robert Stevenson, «Tornar [Torgh], Roberto [Turner, Robert]», en Oxford Music Online. Grove Music Online, ed. online en 2001 $<$ https://doi.org/10.1093/gmo/9781561592630.article.28169>; el artículo digital corresponde a la entrada en el tomo 25 de The New Grove Dictionary of Music and Musicians, ed. Stanley SAdie (2a ed. London: MacMillan, 2001).

5 Proceso, António Pinheiro, Évora, 1596/1605/Arquivo Nacional Da Torre DO Томво, Lisboa, Tribunal do Santo Ofício, Inquisição de Évora, processo 8138, sin foliación, proceso, António Viegas Varela, Évora, 1626, 1629-1631/ArQuivo NACIONAL DA Torre do Tombo, Lisboa, Tribunal do Santo Ofício, Inquisição de Évora, processo 9848, esp. fols. 41v-44v. Los dos procesos muestran el enraizamiento de Pinheiro y de 
António Pinheiro estaba casado con la cristiana vieja Margarida Pinta. La pareja tenía cinco hijos, que nacieron entre 1553/1554 y 1602. João, nuestro protagonista, fue bautizado el 11 de julio de 1596 en Vila Viçosa. Con su hermano y tres hermanas se crió en un ambiente muy especial. La corte ducal en Vila Viçosa pertenecía a los más brillantes de la península ibérica. Formaba el centro de un vasto dominio señorial, impresionaba a los visitantes con su arquitectura esplendorosa y su irradiación cultural y -no olvidemos- contaba con la presencia casi constante de los duques y sus familiares. En la Vila Viçosa bajo dominio brigantino, João Pinheiro creció con la música de la capilla dirigida por su padre y conocía otras facetas del último renacimiento y humanismo. Y podía tener una idea de lo que era el poder ... de un duque, de la Inquisición y de la ascendencia. João Pinheiro pasó unos años decisivos en su ciudad natal, otros en Évora. Si allí estuvo ya en los años alrededor de 1607 con el padre y la familia, no es cierto. De todos modos, por 1610 empezó a estudiar en la universidad eborense ${ }^{6}$.

\section{Filosofía y medicina: Évora y SAlamanca}

A diferencia de los logros culturales, la teología, la filosofía y las ciencias del seiscientos ibérico tienen mala reputación y el mundo académico está considerado como anquilosado y poco productivo. Sin embargo, hay que matizar. Como en toda Europa, los estudiantes españoles y portugueses en las facultades de artes recibían una esmerada

su familia en el mundo judeoconverso y documentan en parte la persecución inquisitorial mencionada, que está completamente registrada en el banco de datos del Arquivo NACIONAL DA TORRE Do Tombo, Lisboa. Aquí, solamente indicamos: Mestre Marcos (Inqu. de Évora, proc. 6493) y Maria Cardosa (Inqu. de Évora, proc. 4299).

6 Proceso, António Pinheiro, Évora, 1596/1605/Arquivo Nacional Da Torre Do Томво, Lisboa, Tribunal do Santo Ofício, Inquisição de Évora, processo 8138, sin foliación; libro de bautismos, Vila Viçosa, Nossa Senhora da Conceição, 1567-1601/ARQuivo Distrital de Évora, paroquias, Vila Viçosa, Nossa Senhora da Conceição, libro de bautismos 1, fols. 362v, 383v y 400v, libro de bautismos, Vila Viçosa, Nossa Senhora da Conceição, 1601-1619/Arquivo Distrital de Évora, paroquias, Vila Viçosa, Nossa Senhora da Conceição, libro de bautismos 2, fol. 14v, proceso, António Viegas Varela, Évora, 1626, 1629-1631/Arquivo Nacional da Torre do Tombo, Lisboa, Tribunal do Santo Ofício, Inquisição de Évora, processo 9848, esp. fol. $42 \mathrm{v}$. 
formación, aristotélica principalmente, que constituía la base imprescindible para las disciplinas mayores y que, al fin y al cabo, fue el punto de partida de cualquier desarrollo científico occidental. En estas circunstancias, en el mundo ibérico del siglo XVII seguía floreciendo la segunda escolástica, que -con su reflexión acerca de la probabilidad, por ejemplo- también en aquella época daba impulsos nada desdeñables al desarrollo filosófico y científico europeo ${ }^{7}$. Además, en las aulas y en los estudios de los centros académicos ibéricos algunos médicos y teólogos ya en la primera mitad del siglo XVII desarrollaban ideas que ponían en duda ciertas bases del pensamiento aristotélico ${ }^{8}$. Así, el mundo universitario en el cual el joven João Pinheiro se sumergía tan estéril no era.

Que el hijo del maestro de capilla de los Duques de Braganza estudió en Évora no sorprende. El viaje de Vila Viçosa solo duraba un día o dos. Además, la familia del joven estudiante tenía bastantes vínculos con la ciudad, sobre todo, en ella vivían algunos parientes. Con las otras universidades de la época, la institución eborense compartía muchas características, al mismo tiempo, mostraba sus particularidades. Así, pertenecía al pequeño círculo de auténticas universidades jesuíticas y estaba vinculado con un colegio de la Compañía. Además, la institución no

${ }^{7}$ Aquí no podemos profundizar la amplia temática poco estudiada; acerca de la reflexión sobre la probalidad, vid. Sven K. Knebel, Wille, Würfel und Wahrscheinlichkeit. Das System der moralischen Notwendigkeit in der Jesuitenscholastik, 15501700 (Hamburg: Felix Meiner Verlag, 2000); el trabajo original enfoca la matematización de la probabilidad en las discusiones acerca de la gracia en los siglos XVI y XVII y el papel fundamental de toda una serie de teólogos españoles en este proceso. Tilman Ramelow ([= Anselm Ramelow OP] Gott, Freiheit, Weltenwahl. Der Ursprung des Begriffes der besten aller möglichen Welten in der Metaphysik der Willensfreiheit zwischen Antonio Pérez S.J. (1599-1649) und G.W. Leibniz (1646-1716) [Leiden-New YorkKöln: Brill, 1997]) se dedica a una temática relacionada y estudia las nociones de posibilidad, libertad y necesidad en el pensamiento metafísico y teológico de la escolástica jesuítica del seiscientos. Fueron pensadores españoles quienes dominaron este discurso y elaboraron ideas que Gottfried Wilhelm Leibniz desarrolló después para su concepto del mejor de todos los mundos posibles.

8 Un ejemplo sería el jesuita y teólogo Pedro Fernández de Torrejón (1594-1645); vid. Petrus Ferdinandius Torreion, Philosophia antiqva ex Arist. et D. Thom. ad octo libros phisicorvm. Expositivis dispvtationibus envcleata (Compluti 1639), y Philosophia antiqva ex Arist. et D. Thom. ad libros de ortv et interitv. Expositivis dispvtationibvs envcleata (Compluti 1641). Como otros pensadores españoles del barroco, el jesuita está prácticamente olvidado. 
tenía facultad de derecho ni de medicina, sino solo ofrecía estudios de artes y de teología así como una formacíon básica. Esta incluía ante todo la enseñanza del latín y tales clases de «gramática» probablemente marcaron el inicio de los estudios de João Pinheiro en las magníficas instalaciones de la universidad de Évora. Después de algún tiempo, el joven entró en la facultad de artes, que a su vez tenía carácter propedéutico. A continuación, con las «súmulas» y la lógica, con la filosofía natural y la metafísica cursó todo el programa de la filosofía aristotélica. En marzo de 1616, João Pinheiro se graduó de bachiller. Como quería seguir con la carrera de medicina, tenía que cambiar de universidad ${ }^{9}$.

A finales del quinientos y en los primeros decenios del siglo XVII, en las aulas universitarias y tabernas cercanas, en las calles y plazas de Salamanca una y otra vez se podían captar retazos del portugués. Había muchos estudiantes lusos en la ciudad, sobre todo, la facultad de medicina atraía a los jóvenes del reino vecino y entre ellos se encontraba un porcentaje altísimo de cristianos con raíces judías. Juan Piñero era uno de ellos. Después de su examen en Évora, el flamante bachiller en artes había cruzado la raya de Castilla, se pasó a Salamanca y allí se matriculó en la facultad de medicina. Con interrupciones llamativas, nuestro protagonista estudió de 1616 a 1628 en las orillas del Tormes, en 1621/1622 y entre 1623 y 1627 no le encontramos en las aulas salmantinas. A lo largo de siete años, cursaba clases de medicina teórica y práctica y de metodología, además adquiría conocimientos de cirugía, visitaba a en-

${ }^{9}$ De las fuentes universitarias eborenses de aquellos años no se ha conservado nada. Sin embargo, la documentación universitaria salmantina conserva un certificado acerca de los estudios de Pinheiro en Portugal: Pruebas de curso, Universidad de Salamanca, 1617/18/Archivo Histórico de la Universidad de Salamanca, 607, fol. 62v. Los estudios eborenses dejaron sus huellas en Pinheiro, aún medio siglo más tarde se acordaría como había memorizado las equipolencias lógicas enseñadas en las clases de las «súmulas»: «Y quando en mi fuera omission de la memoria, me disculparàn los muchos años que ha decorè aquellos versos...»; $c f$. Juan Baptista PIÑERO, Escvdo de la verdad, que desvanece clavas, si en lo sophistico Hercvleas, siempre en lo vero pigmeas: y aniqvila cierta anvlacion de vn medico joven, incierta en lo qve promvlga, anulada en lo que enxerta (Sevilla 1661), capítulo 2, respuesta al capítulo 3. Que el estudiante tenía familia en Évora parece más que probable, pues los parientes procesados por la Inquisición que hemos mencionando principalmente vivían en la ciudad. 
fermos y cumplía con otros requisitos académicos como unas «conclusiones», una «disputatio», en mayo de $1619^{10}$.

En Salamanca, como en todas universidades de la época se enseñaba la medicina hipocrático-galénica, que sí había conocido sus innovaciones en tiempos del humanismo, pero que seguía siendo el venerable sistema doctrinal desarrollado a lo largo de muchos siglos. Juan Piñero se formó con esta tradición aún inquebrantable si bien estudiantes inquietos como él estaban receptivos a nuevas ideas. Compañeros con un espíritu abierto los podía encontrar nuestro protagonista en las aulas salmantinas. Así, en sus años coincidía con algunos estudiantes, cristianos nuevos lusos y futuros médicos todos, que podemos vincular con un círculo de hombres jóvenes de las mismas características, que se detecta en los años alrededor de 1630 en la Universidad de Alcalá y que probablemente era un semillero de ideas deistas. Posteriormente, Juan Piñero desarrollaría una relación con dos hombres que habían pertenecido a aquel grupo complutense ${ }^{11}$.

Quizás, cierta curiosidad intelectual moviese a Juan Piñero a interrumpir su estancia en las orillas del Tormes para ampliar su horizonte y estudiar también en otra universidad, sería la explicación más lógica para sus ausencias de la Universidad de Salamanca. Sin embargo, no sabemos dónde se encontraba en 1621/1622 y entre 1623 y 1627 . Fue probablemente a finales del último año que el futuro médico se volvió a las aulas salmantinas. Y en 19 de octubre de 1628 , cuando curiosamente se matricula para el año académico finalizado, aparece por última

${ }^{10}$ Libros de matrículas, Universidad de Salamanca/ArChIVo Histórico DE LA Universidad De SalamanCa, 1615/16/323, fol. 143r; 1616/17/324, fol. 140v; 1617/18/325, fol. 142r; 1618/19/326, fol. 140r; 1619/20/327, fol. 140v; 1620/21/328, fol. $142 \mathrm{v} ; 1621 / 22 / 329$, passim; 1622/23/330, fol. 141v; 1623-1627/331-334, passim; 1627/28/335, fol. 43r, y 1628-1630/336-337, passim; y Pruebas de curso, Universidad de Salamanca/Archivo Histórico de la Universidad de Salamanca, 1617/18/607, fol. $62 \mathrm{v} ; 1618 / 19 / 608$, fol. 58r; 1619/20/609, fols. 51r y 58r; 1620/21/611, fol. 54r; 1622/23/615, fol. 52r, y 1623/24/616, fol. 56r. Acerca de los estudiantes portugueses en Salamanca, hay toda una serie de estudios de Ángel MARCos DE Dios, aquí solo citaremos su «A Universidade de Salamanca e Portugal no período Barroco», en D. Francisco Manuel de Melo e o Barroco Peninsular, eds. Marta Teixeira Anacleto, Sara Augusto y Zulmira SANTos (Coimbra-Salamanca: Universidad de Salamanca-Universidade de Coimbra, 2000) págs. 79-94: 81-82 y 88-91.

11 Profundizaremos en el tema infra. 
vez en la documentación universitaria. En aquel momento, le encontramos como bachiller en artes y «pasante», que probablemente se preparaba para el examen ${ }^{12}$. No queda claro con qué grados Juan Piñero terminó sus estudios salmantinos. Es posible que por el alto coste no se licenciara en Salamanca, sino que obtuviera el título en una de las universidades menores, que cobraban menos. Fuera como fuese, a finales de los años 1620 en la vida de nuestro protagonista comenzó una nueva etapa.

3. Fragmentos de una vida: Lisboa, Valencia, Molina de ARAGÓN Y SEVILla

En 1629/1630, el mercader António Viegas Varela (ca. 1589-?) fue procesado como judaizante por la Inquisición de Évora y a lo largo de las audiencias testificó contra dos hijos de un tío materno. El menor, músico como el padre, ya estaba muerto, el mayor, «medio cristiano nuevo» como su hermano, era nuestro protagonista João Pinheiro. E1 hijo del maestro de capilla de los Duques de Braganza había encontrado a su primo Viegas Varela en 1627/1628 cuando venía de Castilla y pasó por Évora. Según la testificación ante el Santo Oficio, en aquel momento los dos hombres se declararon mutuamente «que creían y vivían en la dicha ley de Moisés» sin profundizar más el tema. Además, Viegas Varela contó a los inquisidores, que João Pinheiro en 1629/1630 era médico en Lisboa y estaba casado con una mujer portuguesa ${ }^{13}$. Nada más sabemos sobre aquella estancia de nuestro protagonista en la capital lusa y las informaciones acerca de su próxima aparición son igualmente escasas. Con ellas, volvemos a España.

Así, de 1633 a 1635 un Juan Bautista Pinero de Lisboa estudió medicina en la Universidad de Valencia. Parece que nuestro protagonista, que ya rayaba los 40 años, con dos cursos profundizó sus conocimientos

12 Libro de matrículas, Universidad de Salamanca, 1627/28/ArChivo Histórico DE la Universidad de Salamanca, 335, fol. 143r.

13 Proceso, António Viegas Varela, Évora, 1626, 1629-1631/ArQuivo NACIONAL DA Torre do Tombo, Lisboa, Tribunal do Santo Oficio, Inquisição de Évora, processo 9848, esp. fols. $42 \mathrm{v}, 49 \mathrm{r}$ y $64 \mathrm{r}-\mathrm{v}$. 
médicos y probablemente se doctoró ${ }^{14}$. En aquel tiempo, Piñero trabó amistad con Rodrigo Enríquez de Fonseca (1614-?). Este cristiano nuevo de raíces lusas y su hermano Luis (1612-?) -ambos médicos (y posteriormente hombres de negocios y catedráticos)- habían pertenecido al círculo de estudiantes ya mencionado, que encontramos en la Universidad Complutense alrededor de 1630. Después de su estancia en Alcalá, Rodrigo Enríquez de Fonseca pasó a la Universidad de Valencia, donde en 1633/34 terminó su formación de médico ${ }^{15}$. Entonces, tal vez ya conociese a Piñero de tiempos anteriores: este en las aulas salmantinas había coincidido con Diego Gómez de Fonseca (c 1599-c 1649), tío de los hermanos Enríquez de Fonseca, y sabemos por la documentación universitaria que ambos estudiantes de medicina tenían unos contactos más estrechos ${ }^{16}$. Como veremos más adelante, el encuentro de 1633/34 entre Piñero y Enríquez de Fonseca tiene bastante importancia para nuestra historia.

Después de su estancia en Valencia, en algún momento entre 1635 y 1650, Juan Baptista Piñero aparece en Molina de Aragón (Guadalajara), donde el doctor era médico de la villa. Allí, había trabado amistad con el funcionario real e historiador Diego Sánchez Portocarrero (16071666) y cuando este, en su magna obra acerca del señorío de Molina,

14 Vid. Amparo Felipo, Francisca Miralles y Francisco Javier Peris, Estudiantes y probanzas de cursos en la Universidad de Valencia (1561-1707) (Valencia: PUV, 2013) pág. 268.

15 Vid. Israël S. RÉvah, Des marranes à Spinoza, ed. Henri Méchoulan, PierreFrançois Moreau y Carsten L. Wilke (Paris: Vrin, 1995) (trabajos ya publicados anteriormente) págs. 271-272; Natalia MuchNiK, Une vie marrane. Les pérégrinations de Juan de Prado dans l'Europe du XVII siècle (Paris: Honoré Champion, 2005) pág. 348; Markus SCHREIBER, «Conversos y librepensamiento. A la búsqueda de algunas huellas (ss. XVI y XVII)», Sefarad 77:2 (2017) págs. 375-403: 385-389, 391-396 y passim, y Marranen. Eine Familie im Schatten der Inquisition, 1497-1688 (München: August Dreesbach Verlag, 2013) pág. 118; Pruebas de curso, Universidad de Alcalá, 1631-1634/ Archivo Histórico Nacional, Universidades, lib. 493, fol. 10r (1633, medicina) y passim, y Expediente Josef Orozco, Casa de Contratación, 1634/35/Archivo General DE Indias, Contratación, 5416, núm. 72.

16 Vid. SchreIBer, Marranen, págs. 95-96, 99, 102-103, 121 y passim; Libros de matrículas, Universidad de Salamanca/Archivo Histórico de la Universidad De SALAMANCA: 1617/18/325, fol. 140r y 1618/19/326, fol. 140r, y Pruebas de curso, Universidad de Salamanca/Archivo Histórico de la Universidad de Salamanca, $1618 / 19 / 608$, fol. $58 \mathrm{v}$ y $1619 / 20 / 609$, fol. $44 \mathrm{v}$. 
tematizó el efecto del ambiente y del clima sobre la población de la zona, se basó en algunas amplias reflexiones científicas y filosóficas de su amigo, que había explicado la materia «con agudeza y nouedad digna de Estampa» ${ }^{17}$. Desafortunadamente, el autor no nos cuenta más sobre Piñero. ¿Cómo había llegado a Molina? ¿Desde dónde? ¿Cuánto tiempo pasó en la villa? Estas y otras preguntas surgen en todo lo relativo a la biografía de Piñero entre 1628 y los años alrededor de 1650. Prácticamente no podemos reconstruir las fases y circunstancias de una trayectoria que al principió llevó a nuestro protagonista de Salamanca a Lisboa; durante la cual aparece en Valencia y Molina de Aragón, y que termina finalmente en Andalucía. Allí, la biografía de Piñero cobra un perfil algo más nítido. Veamos los detalles.

En torno a 1660, nuestro médico vuelve a aparecer en la documentación inquisitorial. Esta vez, se trata de informaciones del Santo Oficio hispánico. Según una testificación ante el tribunal de Lima, Piñero vivía en Sevilla alrededor de 1650. Nos enteramos de que estaba casado por segunda vez, de que su mujer cristiana vieja se llamaba Leonor y de que era amigo y antiguo compañero de estudios de Rodrigo Enríquez de Fonseca; otras referencias son vagas u obviamente equivocadas ${ }^{18}$. Aparte de las informaciones inquisitoriales acerca del galeno sevillano Juan Piñero ${ }^{19}$, hay algunas publicaciones científicas de aquellos años, que arrojan una luz interesante sobre nuestro protagonista. Entre ellos, se encuentran los únicos testimonios directos que tenemos de él.

\section{INCEPIT CONTROVERSIA: SEVILla}

En una sección de su Tribvnal medicum, magicvm, et politicum, Gaspar Caldera de Heredia (1591-?) ponía una «Quaestio unica»: «An in

17 Vid. Diego Sánchez Portocarrero, Historia del Señorio de Molina. Segunda parte, t. 1, mediados del siglo XviI/Biblioteca Nacional de España, Madrid, Manuscritos 1556, fol. 9v. Presentamos este documento ya anteriormente en SCHREIBER, «Conversos y librepensamiento», pág. 397.

18 Vid. RÉvah, Des marranes à Spinoza, págs. 271-272; Muchnik, Prado, pág. 348, y SCHREIBER, Marranen, págs. 151, 159 y 164.

19 Con este nombre aparece en la documentación. 
omni affectu, qui sanguinis mißionem exoptat, à sanguinis mißione, ex talo semper incipiendum?»Y seguía el médico hispalense:

Haec inter nostros doctores incepit controversia, anno 1653. quidam doctus, hanc novam inauditam, neque unquam in quaestionem tractam, a Hippocratis tempore existimavit; ideo sectam dixit, \& inauditum dogma, ac ejus auctorem methodi praeversorem nuncupavit, quia de tradita antiquorum via deviavit; $\ldots{ }^{20}$.

Efectivamente, la discusión en Sevilla ya había comenzado algo antes de lo que constataba Caldera de Heredia. En 1652, Luis Pérez Ramírez, «quidam doctus», publicó su Defensa de las sangrías de el tobi$l l o^{21}$. El médico y catedrático jubilado de la universidad hispalense reaccionaba ante los ataques a sus ideas «inauditas» de sangrar en el pie; sobre todo se dirigía contra Diego de Valverde Orozco, médico de la Inquisición sevillana, quien poco antes le había criticado duramente con un tratado corto $^{22}$. El libro de Pérez Ramírez provocó una auténtica avalancha de publicaciones. ¡En 1653, en Sevilla y otros sitios salieron nada menos que nueve tratados médicos! ${ }^{23}$ En su mayoría, defendieron

20 Caspar Caldera de Heredia, Tribvnal medicum, magicvm, et politicum. Pars prima (Lugduni Batavorum CiojoclviII [= 1658]) pág. 261.

${ }^{21}$ Luis Pérez Ramírez, Defensa de las sangrias de el tobillo (Sevilla 1652).

22 [Diego de Valverde Orozco] Controversia medica, en que se disputa, si conforme al Arte y Methodo de Medicina, se ha de variar la parte, do se ha de sangrar, segun las diferencias de las enfermedades, y partes afectas: o si siempre en qualquiera enfermedad, se aya de començar sangrando del touillo [Sevilla 1652?].

23 A saber: Diego de Valverde Horosco [sic], Proteccion de la doctrina de Hipocrates y Galeno, Acerca del methodo de curar por sangrias, segun las diferencias de las enfermedades, y partes afectas: y Aniquilacion de la nueua opinion de sangrar de los touillos (Sevilla 1653); Balthasar DE OROBIO, Controvertitvr, vtrum materialibvs morbis inchoantibus sang. missio revulsiua, iuxta Hippocratis, \& Galeni dogmata per distantissimas venas effici debeat? (Sevilla 1653); Francisco Duarte DE TÁvorA, Copia de vn parecer a cerca del vso de las samgrias del tovillo en todas las mas enfermedades que piden sangria. ... (Sevilla 1653); Pedro De AhumadA, Qvestion en la qval se intenta averigvar como, y de que venas, y de que partes se deba sangrar en las enfermedades que curamos, segun la idea, y naturaleza de la enfermedad, y si se deben variar las dichas sangrias, segun la variedad de las enfermedades, y de sus tiempos, y de los sitios, y lugares mal afectos que padecen (Sevilla 1653); Alonso Granado, Dvdas a la aniqvilacion y defensa de las sangrias del touillo (Sevilla 1653); Duarte NúÑEZ DE ACOsTA, Tratado Practico del Vso de las sangrias assi en las enfermedades particvlares, como 
la práctica tradicional de aplicar la sangría principalmente en el brazo; solo Alonso Granado y Luis Rodríguez de Pedrosa (ca. 1600-1673), catedráticos de medicina en Sevilla y Salamanca respectivamente, acudieron en ayuda de Pérez Ramírez.

Las publicaciones de 1653 formaron el apogeo de una discusión que seguiría después muchos años e incluiría a algunos de los médicos más renombrados de la época. Ya en 1654, intervino Gaspar Bravo de Sobremonte Ramírez (1603-1683), catedrático vallisoletano y futuro médico de cámara de Felipe IV y Carlos II. En sus Resolutiones Medicae, leídas en toda Europa, presenta detalladamente la sangría y discute las posiciones de la controversia hispalense apoyando la posición mayoritaria $^{24}$. Unas ideas contrarias las expondría Gaspar Caldera de Heredia en el ya mencionado Tribvnal medicum, magicvm, et politicum cuatro años más tarde ${ }^{25}$ y cuando Gaspar Bravo de Sobremonte Ramírez con mordacidad atacaba «quemdam Bombilium Hispalensem» en la tercera edición de sus Resolutiones Medicae de 1662, se refería a Caldera latinizando su nombre a través del griego ( $\beta$ o $\mu \beta \lambda$ tós, bombylius, vasija de cuello angosto ${ }^{26}$. Podemos identificar toda una serie de publicaciones adicionales que, después de 1653, conectaron con la discusión sevillana acerca de la sangría. Entre ellos destacan tres textos cuyo autor no se une ni a uno ni a otro de los dos bandos. Se trata del doctor Juan Baptista Piñero ${ }^{27}$.

en las calenturas (Xerez 1653); Pablo ARIAS De Luna, Tratado de la defensa de la vena basilica para la cvra de las enfermedades agvdas (Xerez 1653); Miguel PÉREz, Parecer, y ervditissima censvra acerca de las sangrias de touillos (Salamanca 1653), y Luys Rodríguez de Pedrosa, Copia del parecer, y aprouacion del vso de las sangrias del touillo [Salamanca 1653?].

${ }^{24}$ Gaspar Bravo de Sobremonte Ramirez, Resolutiones Medicae (2a ed. Lvgdvni 1654).

25 Cf. Caldera de Heredia, Tribvnal, esp. págs. 261-286.

${ }^{26}$ Cf. Gaspar Bravo de Sobremonte Ramírez, Resolvtionvm, \& Consultationum Medicarum tertia editio (Lvgdvni 1662) págs. 651-661.

${ }^{27}$ Los libros de Piñero y los tratados relacionados los presentaremos en los párrafos siguientes. Aquí siguen las publicaciones restantes: Juan Lorenco Estelrique, Tratado breve, y parecer acerca del methodo de cvrar con sangrias, segun las diferencias de las enfermedades del cuerpo humano, y partes afectas (Xerez de la Frontera 1654); Caspar Caldera de Heredia, Tribvnalis medici illustrationes et observationes practicae (Antuerpiae MDCLXIII); Ioannes Lazarus GuTIÉRREZ, Febrilogiae lectiones pincianae... 
En 1655, nuestro protagonista vivía en la baja Andalucía. Entonces, el médico de cámara del Conde de Niebla intervino en la controversia de los galenos sevillanos. Con su Concordia de la controversia sobre el sitio de la sangria quería conciliar a sus colegas enfrentados ${ }^{28}$. Sin em-

(Lugduni 1668); Duarte NúÑEz DE AcostA, Apologia necessaria, y vtil en el exercicio practico de la Medicina, por resolucion de dos questiones, que con novedad se discuten, no poco arduas: La primera, si en los decubitos, ó raptos de humor à la cabeça, se deba purgar con medicamento electivo? La segunda, si en las Perlesias, que suceden à las Appoplexias, se aya de sangrar del lado enfermo? [s.l. s.a.]; Fernando SuÁrez, Antipologia Medica en respvesta de vna apologia del ervditissimo doctor Dvarte Nvñez de Acosta [...] sobre la decision de dos graves dificvltades, que inquieren, si en el rapto incipiente de humor a la Cabeça, convenga medicamento electivo? Y si en la perlesia en que se empezo a descargar la apoplexia, se deva sangrar del lado Paralitico? [s.1. s.a.]; Duarte NúÑEZ DE AcosTA, Lvminar menor, que con lvz participada de los mayores Autores, resplandece a vista de tenebrosas calumnias. Uentilanse nveuamente las dos questiones de purgar los humores, que hazen decubito arriba: y la de sangrar del braço en los afectos superiores pendiente de fluxion: ... (s.1. 1674); Joan Baptista OrIvaI, sive Orivarri et de Monreal, Propugnaculum Hippocraticae ac Galenicae Doctrinae de Febrium Putridarum in principiis per Purgationem, \& Sanguinis-Missionem curatione: commentaria duo complectens [...]. Accessit III. Disputatio Antipodophlebotomia contra Gasparem Caldera, Medicum Hispalensem, \& reliquos ex Talo Venae sectionem profitentes (Lugduni MDCLXXVIX [1678]); Álvaro Tenorio De Leon, Atomos, que nuevamente se han descubierto con las Luzes de Apolo, en la controversia cèlebre del vso de las sangrias, assi en los afectos superiores, como en las calenturas. Respondese a los argvmentos con que el Doct. D. Iuan Moyano pretende impugnar la comun sentencia de los Autores, que venera el Arte por Principes, cuya doctrina se explica, y prueba con razon conforme à la que el Doct. Acosta en el Luminar y otros Tratados enseña [s.l. ca. 1680]; Pedro Honofre Estevan, Tratado breve, y antorcha lvminosa: ... ([Mallorca] 1681), y Francisco PÉREZ de TABORA [sic], Tratado contra el abvso de sangrar siempre del tovillo En todas enfermedades vniversales, y particulares de partes superiores (Sevilla 1682). En este último caso el autor coincide con Francisco Duarte de Távora, ya mencionado como autor. La siguiente publicación, Álvaro Tenorio DE León, Laurel precioso, que de los rayos defiende, y a los triunfantes corona: disuelvense las agudas instancias con que el Doct. D. Juan Moyano ... se opone á la defensa que hazen los Atomos de la sentencia comun, hija legitima de los Principes antiguos, que venerámos por textos, y de todos los Autores clasicos, que con acierto han escrito en la via racional, y methodo del Arte Medicinal [s.l. s.a.], no la hemos consultado y la conocemos solo a partir del cátalogo de la Biblioteca Complutense. Antonio Hernández Morejón (Historia Bibliográfica de la Medicina Española, t. 5 [Madrid 1847] págs. 362-364) menciona algunos tratados más, de los cuales, sin embargo, no hemos encontrado ningún rastro.

28 Juan Baptista PIÑERo, Concordia de la controversia sobre el sitio de la sangria, en los principios de las enfermedades (Sevilla 1655). 
bargo, detrás de la fachada pacífica del libro se encontraban demasiadas provocaciones como para calmar los ánimos. Hasta 1661, Piñero se enredaba en una disputa cada vez más agresiva con dos colegas. Sobre todo, se libraba una auténtica batalla argumentativa con Duarte Núñez de Acosta (ca. 1606-ca. 1685). Este ya había participado en 1653 en la disputa hispalense con una publicación, que fue criticado por Piñero en su Concordia. Seguirían -en una publicación de 1659- sendas cartas impresas de los dos contrincantes ${ }^{29}$. Hacia 1660, Núñez de Acosta atacó a su contrincante en su Clava de Alcides... (Jerez de la Frontera ca. 1660) y Piñero respondió al año siguiente con su Escvdo de la verdad, que desvanece clavas, si en lo sophistico Hercvleas, siempre en lo vero pigmeas: $y$ aniqvila cierta anvlacion de vn medico joven, incierta en lo que promvlga, anulada en lo que enxerta ${ }^{30}$.

\section{Fundamentos inseguros: UNA CRISIS DEL PENSAMIENTO}

El tono beligerante de las publicaciones de Núñez de Acosta y de Piñero como de otras contribuciones a la controversia acerca de la sangría es un indicio más de que estamos ante una disputa que trascendía el carácter de una discusión científica especializada. Efectivamente, los cimientos del discurso médico empezaban a tambalearse. A lo largo de dos milenios, se había originado un corpus doctrinal cuya columna vertebral era la patología humoral y esta requería la sangría como terapia

29 En Juan Baptista PIÑERo, Propvgnacvlo de la Concordia, sobre la Controversia del sitio de la sangria, en los principios de las enfermedades superiores (Écija 1659), se contienen la carta de Núñez de Acosta y la repuesta de Piñero.

${ }^{30}$ El segundo adversario de Piñero se llamaba Juan Moyano de Medina y pertenecía al bando de los progresistas. Al parecer, este médico también escribió contra Piñero. Aparte de la mención de su publicación en el Escvdo, el libro rarísimo solo lo conocemos a través del catálogo de la Biblioteca Geral da Universidade de Coimbra: Juan MoyAnO DE Medina, Anulacion de el tratado de concordia, que compuso el doctor D. Juan Piñero, y especialemente en lo tocante a punto de concordia... (Sevilla 1660). Los Libros de matrícula del Archivo Histórico de la Universidad de Salamanca muestran que Núñez de Acosta estudió allí entre 1619 y 1626, Piñero seguramente lo conocía desde aquellos tiempos. Acerca de Duarte Núñez de Acosta, véase también Poesías latinas de Duarte Núñez de Acosta, ed. Luis Charlo Brea (Cádiz: Publicaciones de la Universidad de Cádiz, 1993). 
clave. Aparte de los textos canónicos de Hipócrates y Galeno, existía un amplio fondo de escritos antiguos, medievales y modernos acerca de las variantes del tratamiento y de su aplicación según los cuadros clínicos ${ }^{31}$. Pero en el siglo XVII, el legado ya no garantizaba la certeza necesaria, sino permitía cada vez más márgenes de exegesis. Un novador como Alonso Granado abogaba por la productividad de la discusión ${ }^{32}$. Sin embargo, esta resultaba más bien destructiva. Los conservadores podían atenerse a la tradición, pero también los progresistas la reclamaban por su causa y Gaspar Caldera de Heredia constataba:

... nos meritis controversiae, cum torno \& cothurno libratis, illam ad limam \& lineam redigimus; \& propriae sententiae fundamenta ita solida jecimus, ut classicam, \& probabilem magis opinionem reddere videremur; ... ${ }^{33}$.

Cada posición se basaba en las autoridades, con un efecto corrosivo: las contradicciones lentamente socavaban el legado científico. Un fenómeno parecido se ha observado en las discusiones teológicas de la época ${ }^{34}$.

Prácticamente, todos los participantes de nuestra controversia se movían en el marco del discurso médico tradicional. No obstante, en algunos momentos se traspasaban los límites fijados. Alonso Granado reconocía las autoridades, pero reclamaba el derecho de superarlas ${ }^{35}$. Gaspar Caldera de Heredia prefería la razón y la experiencia a la tradición ${ }^{36}$ y Luis Pérez Ramírez osaba cuestionar la infalibilidad de doctos canonizados como Galeno y alegaba la experiencia:

31 Ya en el siglo Xvi hubo una amplia discusión acerca del sitio correcto de la sangría. Sobre la historia de la terapia, el mejor estudio sigue siendo el de Josef BAUER, Geschichte der Aderlässe (München: Verlag von E. H. Gummi, 1870).

32 Granado, Dvdas, inicio.

33 Caldera de Heredia, Tribvnal, pág. 261.

34 Alan Charles Kors, Atheism in France, 1650-1729. The Orthodox Sources of Disbelief (Princeton, NJ: Princeton University Press, 1990).

35 Granado, Dvdas, passim.

36 Caldera de Heredia, Tribvnal, esp. págs. 261-286. En el mismo libro se encuentra el tratado del médico acerca de la peste de 1649 en Sevilla (trabajo de una tremenda actualidad). En el prólogo (pág. 505), Caldera de Heredia, que con sus colegas luchó contra la epidemia, destaca el carácter empírico del texto y recalca el valor de la expe- 
El tiempo va descubriendo mucho, porque es el mejor Maestro, y de aqui a cien años, o cinquenta, aurà descubierto otras cosas que aora no nos passan por el pensamiento ${ }^{37}$.

Juan Baptista Piñero asimismo pertenecía a los autores que en algún momento abandonaban la base discursiva establecida, sin embargo, llegaba a unas conclusiones más subversivas que sus colegas.

La Concordia de la controversia sobre el sitio de la sangria fue la contribución principal de Piñero a la disputa hispalense. Al mirar más detenidamente el tratado, reconocemos que la temática de la discusión era más compleja que la simple alternativa entre dos sitios de una terapia. Los retos ya comenzaban con el diagnóstico. Para Piñero y sus colegas eran importantes el lugar, el tipo y los «tiempos» de la enfermedad, la localización y el movimiento de la «fluxión» de los humores, el sistema vascular y toda una larga serie de otras circunstancias y detalles. A consecuencia, la variedad de los cuadros clínicos requería un instrumentario terapéutico diferenciado. Así, existía una sangría «derivativa» y otra «revulsiva», algunos médicos también conocían una forma «evacuativa», tres variantes que se aplicaban en un cuadro clínico concreto en diferentes momentos y sitios. La disputa hispalense sobre todo giraba alrededor de la cuestión importante: si había que aplicar una sangría «revulsiva» del tobillo en vez del brazo en el principio de las enfermedades superiores, lo que proponían los innovadores y lo que enormemente incrementaba la importancia de este tipo de la terapia.

Ante esta situación, la posición de Piñero resulta interesante porque desarrolló su propia teoría. Según unas ideas elaboradas sobre la «revulsión» y la «derivación», propagaba en las enfermedades superiores la sangría de arriba en algunos casos y la de abajo en otros, mientras que los tradicionalistas en la misma situación preferían el brazo y los innovadores el pie. Piñero ofrecía una concordia, que según él ya existía porque los contrahentes no podían menos de sostener sus ideas. ¡Desafortunadamente, ellos mismos no lo sabían! La inevitabilidad de su posición diferenciada Piñero la deducía de su idea de que en la medicina

riencia para él: «... liber enim naturae est optimus docendae Medicinae magister, ex quo plura quam ex scholis omnibus semper didici...».

37 PÉrez Ramírez, Defensa, fol. 14r. 
no existían proposiciones o leyes universales, sino solamente casos concretos. Las generalidades y sutilezas metafísicas eran cosa de los filósofos, la medicina solamente tenía que ver con particularidades. Con estas ideas, que tenían un trasfondo empírico y de alguna forma enlazaban con el nominalismo escolástico, Piñero ponía en duda toda la tradición médica. Y dió un paso más. No tenía mucha confianza en las capacidades cognoscitivas humanas y radicalmente cuestionaba el saber humano: la medicina como otros saberes ofrecía más bien opiniones que ciencia rigurosa ${ }^{38}$.

En sus contribuciones posteriores a la controversia de la sangría, Piñero confirmaba sus posiciones. Aunque sus argumentaciones científicas concretas se mueven dentro de los límites del discurso médico de la época, en sus reflexiones epistemológicas nuestro protagonista completamente ponía en duda los fundamentos de su arte:

No solo digo que la Medicina Galenica no es sciencia rigurosa, ni aun en lo theorico; pero afirmo que de objectos insensibles no se puede naturalmẽte alcançar alguna: porque dellos no se puede probar principio à priori, ni propriedad alguna, si no es opinatiuamente; y opinion excluye sciencia $^{39}$.

¡Menuda provocación! Además, Piñero subrayaba su escepticismo radical y resulta notable que se refería entre otros escritos a uno de los tratados más fulminantes de la corriente filosófica: estamos hablando de Qvod nihil scitvr (1581) de Francisco Sánchez (1550-1623) ${ }^{40}$. Así, en sus publicaciones nuestro protagonista mostraba unas ideas bastante subversivas, que con su carácter iconoclasta inevitablemente escandalizaban a defensores de la tradición como Duarte Núñez de Acosta. Este, también poeta y latinista consumado, incluso dedicó dos mordaces poemas a su contrincante ${ }^{41}$ y en otros versos no menos agresivos, vernácu-

${ }^{38} C f$. Piñero, Concordia. Piñero también enfoca las enfermedades inferiores, para los cuales asimismo propone un tratamiento diferenciado.

39 PIÑERo, Escvdo, § 18.

40 Una edición, traducción e introducción la encontramos en Francisco SÁNCHEZ, Qvod nihil scitur. Daß nichts gewußt wird, ed. Kaspar Howald (Hamburg: Meiner Verlag, 2007).

${ }^{41}$ Se trata de un dístico («In te versa vide, quae contra spicula iactas: / Clades, quam timui, stat sicophanta tibi»), y del siguiente epigrama: 
los esta vez, se burlaba de un «Medico Seuillano que auia curado a vn perrito de falda con sangrías de tobillo» ${ }^{42}$.

Yosef Kaplan, probablemente el único historiador que hasta ahora ha enfocado sistemáticamente nuestra discusión hispalense, nos presenta una cultura científica anquilosada y completamente desvinculada de los avances de la revolución científica del siglo XVII ${ }^{43}$. Sin embargo, solo estudió los años 1652/1653 y no se daba cuenta de que la controversia tenía unas dimensiones mucho más amplias. Al mirar toda la disputa detenidamente, se perfila un sistema doctrinal que ya padecía de virulentas contradicciones internas. Al mismo tiempo, médicos como Gaspar Caldera de Heredia o Gaspar Bravo de Sobremonte Ramírez se mostraban receptivos a nuevas ideas científicas: el último en su Resolvtionvm, \& Consultationum Medicarum tertia editio (1662) junto con su tratamiento de la sangría, su aportación a la discusión sevillana y el «Apologeticon Contra nouum quemdam Bombilium Hispalensem...» presentaba y aprobaba la doctrina de William Harvey sobre la circulación de la sangre ${ }^{44}$. Además, hombres como Luis Pérez Ramírez aceptaban la posibilidad de superar con nuevos conocimientos empíricos los teoremas de las autoridades clásicas, mientras que Juan Baptista Piñero abogaba por un escepticismo radical.

Al enfocar el mundo ibérico en el primer libro de su monumental trilogía sobre el Radical Enlightenment, Jonathan I. Israel habla del «Intellectual Drama in Spain and Portugal», donde las primeras innovaciones científicas y filosóficas solamente las identifica en los plantea-

Impostor tua non curans, mea dicta recurvas:

Vtraque, vt efficias sana, medere tuis.

Si bona dum carpis, quia non benè percipis, erras:

Nè prius haec carpas, (emule) quam capias.

Si fingis me erraße, erras: si vendicor, horres:

Te cum non pigeat fingere, ferre decet.

$C f$. Duarte NúÑez de Acosta, Clava, fol. 54r y pág. final.

42 Duarte Núñez de Acosta, Mvseo, 1685/Biblioteca Nacional de España, Madrid, Manuscritos 3891, pág. 428.

$43 \mathrm{Vid}$. Yosef Kaplan, From Christianity to Judaism. The Story of Isaac Orobio de Castro, trad. del hebreo (Oxford: Littman Library, 1989) págs. 67-75.

44 Bravo de Sobremonte Ramírez, Resolvtionvm, \& Consultationum Medicarum tertia editio. 
mientos de los «novatores» antes y después de $1700^{45}$. Es la narrativa habitual. Sin embargo, hay que matizar. Las ideas bastante revolucionarias de los «novatores» tenían sus antecedentes. A mediados del siglo XVII, una fermentación ya estaba en marcha, entre los médicos sevillanos y en otros ambientes. Los participantes de nuestra disputa hispalense sentían muy bien la crisis y defensores de la tradición como Diego de Valverde Orozco o el catedrático salmantino Miguel Pérez veían amenazadas la república y la religión ${ }^{46}$. Incluso, las autoridades empezaban a interesarse por la discusión ${ }^{47}$. El cambio futuro ya se anunciaba. Los médicos desempeñarían un papel destacado y Sevilla sería un centro importante.

\section{El «CORRUPtor» Del «CORRUPtor»: PiÑero, Prado y SPINOZA}

En sus aportaciones a la discusión hispalense, Juan Baptista Piñero se muestra bastante reticente en cuanto a sus circunstancias personales. Su posición de médico de cámara de un importante señor, sin embargo, no nos oculta. Alrededor de 1655, atendía al Conde de Niebla. Este, Gaspar Juan Alonso Pérez de Guzmán el Bueno (1630-1667), como hijo y sucesor futuro del IX Duque de Medina Sidonia (a partir de 1664) pertenecía a una de las casas más poderosas de la monarquía, que, no obstante, en aquellos años se encontraba en una profunda crisis como consecuencia de la conspiración del linaje contra el rey en $1641^{48}$. Como

$45 \mathrm{Vid}$. Jonathan I. IsRael, Radical Enlightenment. Philosophy and the Making of Modernity, 1650-1750 (Oxford: Oxford University Press, 2001) págs. 528-540.

46 Cf. [Valverde Orozco] Controversia medica, passim y Diego de Valverde Horosco [sic], Proteccion, prólogo. Pérez (Parecer, pág. 31) se refiere así a una de las conclusiones de la nueva teoría: «Cierto que no acabo de dar credito, que esta proposicion es parto del entendimiento de vn hombre docto, Catholico Cristiano, pues no solo se opone a la verdad medica, sino a la Catolica y Christiana que professamos».

47 Referencias hay en las siguientes cuatro publicaciones: PÉREZ, Parecer, pág. 1; Rodríguez de Pedrosa, Copia del parecer, inicio; de Távora, Copia de vn parecer, inicio, y PÉrez de TABora, Tratado, pág. 45, los dos últimos autores son idénticos.

48 En Piñero, Concordia, el inicio con la dedicatoria al Conde de Niebla y el correspondiente blasón de la casa de Medina Sidonia reflejan la relación de Piñero con la casa andaluza. Además, al final del libro hay un extraño escudo portugués. ¿Tiene que ver con el impresor sevillano de origen luso? ¿Es una alusión a la relación de la casa 
«humilde vasallo» del Conde de Niebla, Juan Baptista Piñero pertenecía a un círculo exclusivo: hablamos de los médicos de cámara lusos de origen judío, que en el mundo hispánico del seiscientos desempeñaron un papel llamativo. Y Piñero a mediados del siglo XVII no solo formaba parte de aquel gremio ilustre, sino también estaba relacionado con toda una serie de hombres de este ambiente particular.

Así, Diego Gómez de Fonseca, antiguo compañero salmantino de Piñero, a finales de los años 30, servía en Sevilla a Fernando Álvarez de Toledo y Mendoza (1595-1667), Marqués de Villanueva del Río, que en 1639 sucedió a su padre como VI Duque de Alba ${ }^{49}$. Su sobrino Rodrigo Enríquez de Fonseca, amigo de nuestro protagonista, antes y después de 1640 era médico de cámara del arzobisbo de Bogotá ${ }^{50}$. Y Duarte Núñez de Acosta, adversario científico de Piñero a lo largo de unos años, fue otro médico de cámara luso con origen judío, quien antes de 1653 estuvo al servició de Juan José de Austria y del Duque de Medina Sidonia, y después de mediados del siglo servía a la casa de Medinaceli ${ }^{51}$. Además, nuestro protagonista entró en contacto con dos otros cristianos nuevos con raíces en Portugal que durante algún tiempo con

de Medina Sidonia con el «rey rebelde» de Portugal? No hay que olvidar que el duque era cuñado de Juan IV. Asimismo, el monarqua luso, gran patrocinador de música, compositor y consumado teórico de la materia, era hijo de Teodosio II de Braganza, al quien António Pinheiro había servido de «mestre de capela», e incluso es posible que este se encargase de la primera formación musical del futuro rey.

49 Cf. Álvaro SÁnchez Durán, «Interacciones entre hombres de negocios de la nación portuguesa y élites políticas en la Monarquía Hispánica: el doctor Andrés de Fonseca y las rentas reales de Málaga (1645)», en Estudios sobre la corrupción en España y América (siglos XVI-XVIII), eds. Francisco Gil MartíneZ y Amorina Villarreal Brasca (Almería: Edual, 2017) págs. 81-104: 86. En este contexto tenemos que mencionar a Henrique Jorge Henriques o Jorge Henríquez. El cristiano nuevo nació alrededor de 1555 en Portugal y desde finales del siglo Xvi hasta su muerte en 1622 fue médico de cámara del Duque de Alba. El renombrado galeno fue suegro de Diego Gómez de Fonseca y otra hija la casó con el hermano de su yerno, quien era el padre de Rodrigo y Luis Enríquez de Fonseca; $c f$. SchreIBER, Marranen, págs. 96-98 y 101.

50 Cf. SchreIBER, Marranen, págs. 133-137.

$51 C f$. NúÑEZ DE ACOSTA, Lvminar menor; Duarte NúÑEZ DE ACOSTA, Invectiva en que se prveba que la epidemia que ha padecido la civdad del Gran Puerto de Santa Maria dende fines de Iunio del año de 680. hasta 18. de Agosto de 681 fue verdadera peste: ... [s.l. s.a.]; Poesías latinas de Duarte Núñez de Acosta, ed. Charlo Brea, y Kaplan, Orobio de Castro, págs. 71-72 y 88. 
sus servicios médicos atendían a poderosos señores y con ellos damos con el «corruptor» del «corruptor» de Spinoza.

En 1653, un tal Balthasar de Orobio (ca. 1617-1687) en Sevilla publicó Controvertitvr, vtrum materialibvs morbis inchoantibus sang. missio revulsiua, iuxta Hippocratis, \& Galeni dogmata per distantissimas venas effici debeat? En el apogeo de nuestra disputa hispalense acerca de la sangría, el médico de cámara del Duque de Medinaceli y excatedrático de medicina apoyaba a sus colegas tradicionalistas y rechazaba las ideas de los innovadores. Poco después, el autor como judaizante sufrió un proceso inquisitorial en Sevilla y más tarde abandonó Castilla para establecerse finalmente en 1662 en la comunidad sefardita de Ámsterdam. A continuación, Isaac Orobio de Castro -así se llamaba después de su conversión al judaísmo- obtuvo cierta fama de autor que defendía la tradición de su nueva religión y en diversos frentes atacaba a sus adversarios. Uno de ellos era Juan de Prado ${ }^{52}$.

De hecho, los dos oponentes habían mantenido durante muchos años una amistad y sus biografías muestran paralelismos significativos. Como Orobio de Castro, Juan de Prado era cristiano nuevo con orígenes en el norte de Portugal. Ambos crecieron en Andalucía, estudiaron medicina y durante algún tiempo coincidieron en la Universidad de Alcalá. Como galenos, los dos volvieron al sur de España, donde Juan de Prado asimismo entró al servicio de un señor poderoso: en 1653, le encontramos en Sevilla como médico de cámara del cardenal Domingo Pimentel de Zúñiga (1585-1653). Este aquel año se pasó a Roma para servir de embajador en la Santa Sede y Juan de Prado le siguió. Así, también abandonó España y como Orobio de Castro después de un rodeo se estableció en la comunidad sefardita de Ámsterdam ${ }^{53}$.

Sin embargo, había una diferencia fundamental entre los dos amigos. Mientras que Orobio de Castro se adaptó perfectamente al nuevo ambiente religioso, social y cultural, Juan de Prado con una clara orientación heterodoxa se enfrentó rapidamente con las autoridades de la comunidad sefardita de Ámsterdam. Y allí, en la segunda mitad de los años 50 , encontró al joven Spinoza. Israël S. Révah, que reconstruyó la rela-

\footnotetext{
52 Cf. Kaplan, Orobio de Castro.

53 Cf. Muchnik, Prado, y Kaplan, Orobio de Castro.
} 
ción de ambos hombres meticulosamente, vio en ella y su contexto criptojudío los «orígenes de la ruptura spinoziana»; una tesis tan sugerente como controvertida. ¿Un hombre «mediocre» como Prado realmente podía inspirar a Spinoza? Cierto, el sistema filosófico del panteísta (o mejor panenteísta) es complejo y tiene su origen en el cartesianismo principalmente. Pero podemos identificar otras fuentes e impulsos: el trasfondo biográfico y familiar de Spinoza por ejemplo, que le vinculaba con el criptojudaísmo ibérico y sus tendencias de «irreligión». Y había el encuentro con Prado. Cuando el futuro filósofo holandés se relacionó con el médico español, era un hombre joven con una inquietud intelectual extraordinaria, que probablemente ya tenía la cabeza llena de ideas, pero que aún no era el pensador consumado. El doctor Juan de Prado, en cambio, tenía más de 40 años, había estudiado, vivido como criptojudío y luego desarrollado un claro ideario deísta. Que tuvo su influencia en Spinoza parece fuera de duda, cuanto más que este se desvinculó de la comunidad sefardita poco después de la aparición del médico heterodoxo en Ámsterdam ${ }^{54}$.

Cuando Isaac Orobio de Castro en 1662 se estableció en la metrópoli holandesa, Juan de Prado, como persona non grata de la comunidad sefardita, ya se había pasado a Amberes. No obstante, a continuación los dos en una corresponencia interesantísima se enfrentaron acerca de la relación entre fe y razón, entre tradición religiosa y reflexión filosófica ${ }^{55}$. $\mathrm{Y}$ es en esta disputa donde aparece el «maldito y detestable» Juan Piñero,

54 Aquí no podemos profundizar la temática ni citar toda la bibliografía acerca de la materia. Las publicaciones más importantes son las siguientes: Israël S. RÉvAH, Spinoza et le Dr Juan de Prado (Paris-La Haye: Mouton, 1959), Des marranes à Spinoza $\mathrm{y}$ «Aux origines de la rupture spinozienne: Nouveaux documents sur l'incroyance dans la communauté judéo-portugaise d'Amsterdam à l'époque de l'excommunication de Spinoza», Révue des Études Juives 123 (1964) págs. 359-431, y Muchnik, Prado, esp. págs. 409-417. Dos trabajos, cuyos títulos ya son reveladores, enfocan el tema desde una perspectiva filosófica y con enfoque más amplio; a saber: Yirmiyahu Yovel, Spinoza and other Heretics, t. 1: The Marrano of Reason (Princeton: Princeton University Press, 1989) y Gabriel AlBiac, La sinagoga vacia. Un estudio de las fuentes marranas del espinosismo (ed. orig.1987, Madrid: Tecnos, 2013). Cada uno nos presenta a su propio Spinoza, pero ambos en él ven sobretodo el filósofo «marrano».

55 El primero en analizar la discusión fue Israël S. RÉVAH en su importante libro Spinoza et le Dr Juan de Prado; véanse además: KaPlan, Orobio de Castro, págs. 122178, y Muchnik, Prado, págs. 448-464. 
que Orobio de Castro conocía personalmente ${ }^{56}$ y que para él era el seductor de su amigo Prado: este «Hebreo de nacion, primero Christiano, despues Judio, y despues ni Judio ni Christiano», le había encaminado hacia la heterodoxia. Toda una andanada la soltó Orobio de Castro contra el «hombre de cortissimo juicio, poco Philosopho y menos Medico [...] y, lo peor, abominable en sus costumbres». Piñero era «loco en su discurir, intrepido en su hablar, amigo de novedades, solicitador de paradoxas». Con esta caracterización, en seguida reconocemos al autor de la Concordia, que en la controversia hispalense acerca de la sangría había sostenido unas ideas bien opuestas a la posición conservadora de Orobio de Castro ${ }^{57}$.

\section{El Misterio Piñero ${ }^{58}$}

Con el «maldito y detestable» médico y filósofo, de varios Piñeros tenemos el último, quien de hecho como primero fue descubierto hace medio siglo por Israël S. Révah. Que podemos identificar al «corruptor» de Juan de Prado con el participante en la discusión científica hispalense y el galeno homónimo sevillano de mediados del siglo XVII parece fuera de duda. También el estudiante de Valencia y el amigo de Sánchez Portocarrero fueron la misma persona. Y todas las circunstancias indican que este portugués ${ }^{59}$ nació como hijo del compositor António Pinheiro

56 En algún momento, Piñero había dado un libro de Pablo de Santa María (ca.13501435) a Orobio de Castro; cf. RévaH, Spinoza et le Dr Juan de Prado, pág. 132 (apéndice documental).

57 Cf. RÉvah, Spinoza et le Dr Juan de Prado, págs. 25 y 109 (apéndice documental), y Des marranes à Spinoza, págs. 248 y 254. En el pasaje acerca del «corruptor» Piñero, Orobio de Castro habla de un anónimo; sin embargo, en varias versiones del escrito en cuestión el nombre aparece al margen. Véase, por ejemplo, Isaac Orobio de Castro, Epístola invectiva, 1664/Ets Haim/Livraria Montezinos, Amsterdam, 48 C 04, $17 \mathrm{v}, 18 \mathrm{r}$ («D. Juan Pinhero»).

58 Retomamos un título de Natalia Muchnik: por una parte, pues el cápitulo correspondiente de su biografía acerca de Juan de Prado (Muchnik, Prado, págs. 346-348) fue el punto de partida de nuestras investigaciones; por otra parte, pues a pesar de la nueva documentación descubierta, el misterio Piñero continúa en cierta medida.

59 En las publicaciones de Juan Baptista Piñero hay bastantes indicios de su origen luso. Aquí no queremos entrar en detalles; solo nos remitimos a la cita de la nota 9 con el claro lusitanismo «decorè». 
en Vila Viçosa y más tarde estudió en Évora y Salamanca. Sin embargo, muchas preguntas quedan sin respuesta. Para nuestra historia, una tiene relevancia particular.

No sabemos cómo y en qué momento Piñero «corrompió» a Juan de Prado ${ }^{60}$. No obstante, sospechamos que para la relación entre ambos, un tercer personaje desempeñó un papel clave. Hablamos de Rodrigo Enríquez de Fonseca. El cristiano nuevo y médico no solo conocía muy bien a Juan Baptista Piñero, sino también a Juan de Prado: este, alrededor de 1630, en la Universidad Complutense con Enríquez de Fonseca había pertenecido a aquel grupo de estudiantes de medicina ya mencionado varias veces. El círculo lo formaba una docena de cristianos nuevos de origen luso, que posiblemente judaizaban. Además, algunos de ellos posteriormente cultivarían ideas heterodoxas más radicales ${ }^{61}$. Rodrigo Enríquez de Fonseca era uno de ellos.

Entre 1656 y 1664, el judaizante y librepensador fue procesado por la Inquisición de Lima y durante la causa, en unas confesiones interesantísimas, desarrolló un claro deísmo. Según Enríquez de Fonseca, su ideario se remontaba hasta sus días estudiantiles en Valencia y el reo presentó a los inquisidores un mallorquín como instigador intelectual. Este Baltasar Casáus -o mejor dicho, Casals-habría introducido a nuestro estudiante en el deísmo en los años $30^{62}$. Sin embargo, quedan dudas. Hasta ahora, del misterioso mallorquín no se ha encontrado la más mínima huella; mientras que Juan Baptista Piñero en Valencia coincidió con Rodrigo Enríquez de Fonseca. ¿Se escondía nuestro protagonista detrás de Casals? A lo mejor, el reo de Lima quería proteger a su amigo.

${ }^{60}$ En la valoración de la influencia de Piñero sobre Prado somos muy cautelosos: solo constatamos que el primero era escepticista y el segundo deista. Además sabemos que ambos se conocían y que Orobio de Castro veía a Piñero como corruptor de Prado. De ninguna manera queremos construir una línea de claras influencias y dependencias, que va de uno a otro y luego a Spinoza. En cualquier caso, la formación del ideario de Prado fue un proceso complejo. Acerca del tema, vid. también:Yovel, Spinoza, t. 1, pág. 67.

61 Vid. Muchnik, Prado, págs. 82-103 y passim, y SchreIBer, «Conversos y librepensamiento», págs. 385-403.

62 Vid. SCHreIBER, Marranen, págs. 159-164: Libro de testificaciones, Madrid, 1663, audiencias, Rodrigo Enríquez de Fonseca, Lima, 4 y 11 de marzo de 1661, ArChivo HistóRico Nacional, Madrid, Inquisición, lib. 1134, fols. 168v, 172r-v y 174r-175v. 
De todos modos, queda claro que por lo menos desde 1633 había una relación entre Piñero y Enríquez de Fonseca. ¿Pero cuándo se conocieron nuestro protagonista y Prado? Podemos pensar en diversas situaciones.

Así, no se puede descartar que Juan Baptista Piñero ya antes de 1633 entrase en contacto con Rodrigo Enríquez de Fonseca y Juan de Prado: no olvidemos que conocía al tío del primero desde sus días salmantinos. Además, en torno a 1630, observamos un ir y venir entre las dos principales universidades de Castilla. Así, los cristianos nuevos portugueses Diego Duarte Serrano (ca. 1608-?), Jorge Núñez y Duarte Méndez (ca. 1611-?), al parecer amigos, a partir de 1627 estaban matriculados en Salamanca antes de seguir su formación académica en Alcalá y unirse allí al círculo alrededor de Prado. Coincidieron por lo menos durante un año con Juan Piñero y quizás se conociesen. En nuestro contexto, el caso de Diego Duarte Serrano resulta especialmente interesante, porque este lisboeta más tarde mostraría una orientación deísta ${ }^{63}$. Aparte de un posible encuentro entre Piñero y Prado antes de 1633, podemos pensar en diversas situaciones posteriores: una destaca y se sitúa en 1652/53. Veamos los detalles.

Entre 1628 y 1650, la biografía de Juan Baptista Piñero queda muy difusa; en cambio, las trayectorias de Juan de Prado y de Rodrigo Enríquez de Fonseca las conocemos bien. En la primera mitad de los años 1630, sus caminos se separaron: Prado más tarde se estableció como médico en la alta Andalucía; Enríquez de Fonseca pasó a Valencia y en 1635 a América, pero tras unos años volvió a España y finalmente se estableció como hombre de negocios en Málaga. Ante la situación cada vez más amenazante para los judeoconversos lusos en Castilla, Enríquez de Fonseca y Prado al mismo tiempo se fueron a Sevilla y en 1653 abandonaron el reino. Es muy probable que Juan Piñero en este momento

63 Vid. SCHreiber, «Conversos y librepensamiento», págs. 388 y 390-391: Libros de matrículas, Universidad de Salamanca/ArChivo Histórico DE LA UNIVERSIDAD DE SalamanCA, $1626 / 27 / 334$, fol. 156r; $1627 / 28 / 335$, fols. 152r-v y 184 r; $1628 / 29 / 336$, fols. $151 r-v$ y $155 r$; $1629 / 30 / 337$, fols. 142 r, 152 v y $154 v$; $1630 / 31 / 338$, fols. $140 v$ y $141 v$, y $1631 / 32 / 339$, fols. 140r y 142r. En los libros con las pruebas de curso de aquellos años, los tres también aparecen; además, allí está documentada la relación entre ellos: Pruebas de curso, Universidad de Salamanca/Archivo Histórico de la Universidad de SAlaMANCA, 1627-1629/625, passim; 1629-1632/628, passim, y 1632-1634/632, passim. Cf. RÉvaH, Des marranes à Spinoza, pág. 279. 
residiera en la metrópoli andaluza; todas las fuentes indican que desde aquellos años hasta su muerte en 1662 vivía mayormente en Sevilla. Que Enríquez de Fonseca encontró a Piñero en 1652/53 lo sabemos con certeza y es bien posible que Juan de Prado en aquel momento entrase en contacto con nuestro protagonista. Sin embargo, según las fuentes, también él había desarrollado ya su ideario deísta en épocas bien anteriores: el papel del «corruptor» Piñero sigue siendo un misterio ${ }^{64}$.

Y sigue siendo cierto misterio el hombre entero, que de sí mismo decía que Dios le había dotado de «letras» y «aciertos» y que se jactaba de tal reputación. Al final de su vida, cerca de Sevilla, Piñero cuidaba de los religiosos jerónimos del monasterio de San Isidoro del Campo y trabajaba en un «tratado del Chocolate, con questiones, y opiniones hasta aora intactas» ${ }^{65}$. Aunque lo afirmaba, modestia no era lo suyo. Cuando leemos sus escritos y las caracterizaciones que de él dejaron sus amigos y adversarios, se perfila un hombre inteligente, culto y muy seguro de sí mismo, que mostraba rasgos de nonconformismo y proselitismo. Por 1660, Duarte Núñez de Acosta describe una tertulia médica con Juan Baptista Piñero dirigiéndose irónicamente a su adversario: «... grandes, y agudas doctrinas, que de su boca deprendimos...» ${ }^{66}$. Además, la caracterización poco halagüeña de Orobio de Castro presenta a nuestro protagonista como libertino que combinaba el pensamiento «escandaloso» con un comportamiento «abominable». El tópico subrayaba la «peligrosidad» del librepensamiento y librepensador Piñero era. ¿Pero era también «peligroso»? Sostenía un escepticismo pronunciado, sin embargo, la corriente epistemológica -tan importante en la cultura del barroco hispánico ${ }^{67}$ - permitía conclusiones muy diversas ${ }^{68}$. En nuestro caso, el reparto de papeles parece bastante claro. Así, tanto Orobio de

${ }^{64}$ Vid. Muchnik, Prado, y Schreiber, «Conversos y librepensamiento», págs. 391392 y passim.

65 Piñero, Escvdo, inicio, fol. 9v, y PIÑERo, Propvgnacvlo, prólogo.

66 Duarte NúÑ̃Z DE AcosTA, Clava, inicio.

67 Vid. Jeremy Robisns, Arts of Perception: The Epistemological Mentality of the Spanish Baroque, 1580-1720 (=Bulletin of Spanish Studies 82:8 [Abingdon 2005]).

68 Acerca del escepticismo y su importancia en la historia del pensamiento europeo, véase el libro clásico de Richard H. Popkin, The History of Scepticism. From Savanarola to Bayle (ed. orig.1960, Oxford et al. 2003). 
Castro como Juan Piñero desarrollaron ideas escepticistas, pero el primero como consecuencia defendía cierta dosis de fideísmo, mientras que el segundo al parecer se inclinó por la ruptura con la tradición ${ }^{69}$.

Sin embargo, queda difusa la imagen de nuestro protagonista, por quien la Inquisición empezó a interesarse poco después de su muerte en $1662^{70}$. Con sus planteamientos epistemológicos, Piñero defendía algunas ideas bastante subversivas; al mismo tiempo, por la falta de una alternativa quedaba vinculado con la medicina hipocrático-galénica. Su enraizamiento en unas doctrinas canónicas acompañado de un malestar con la tradición le unía con otros galenos de su tiempo. En cuanto a sus posiciones religiosas y filosóficas, el escepticismo probablemente llevó a Piñero a una ruptura más clara con la tradición. Según Orobio de Castro, nuestro protagonista no era «ni Judio ni Christiano» y quizás como Juan de Prado y Rodrigo Enríquez de Fonseca sostuviese ideas deístas. Los tres judeoconversos con su librepensamiento en la España de mediados del siglo XVII reflejaban una fermentación intelectual que anunciaba cambios venideros ${ }^{71}$. Aquella inquietud tenía raíces en la experiencia religiosa y sociocultural muy particular de los cristianos nuevos lusos, pero sobre todo se nutría del ambiente intelectual de las universidades ibéricas. Con su enseñanza ante todo aristotélica, ponía a disposición las herramientas para una reflexión crítica, que permitía la superación de sus propias bases. Influencias de fuera sí había, pero la crisis era un desarrollo hasta cierto grado autóctono ${ }^{72}$. Y a traves de Juan

69 Acerca de Orobio de Castro, vid. KaPlan, Orobio de Castro, págs. 313-322.

70 Vid. RÉvaH, Des marranes à Spinoza, pág. 271.

${ }^{71} \mathrm{La}$ mejor presentación de este proceso posterior sigue siendo el valioso estudio de Olga Victoria Quiroz-Martínez, La introducción de la Filosofía Moderna en España. El Eclecticismo Español de los siglos XVII y XVIII (Ciudad de México: El Colegio de México, 1949). Uno de los muchos méritos de la autora consiste en el enfoque del escepticismo y probabilismo como fuerzas motrices de las innovaciones filosóficas y científicas de los «novatores».

72 En esto discrepamos de Natalia Muchnik quien, en su biografía de Juan de Prado, intenta reconstruir las fuentes y los orígenes del pensamiento de su protagonista. Aparte del criptojudaísmo, desde el averroísmo radical bajomedieval pasando por el estoicismo y el epicureísmo hasta Descartes y Hobbes, e incluso el libertinage érudit y la revolución científica prácticamente alega todas las corrientes intelectuales heterodoxas e innovadoras de la época como posibles influencias, mientras que minimiza el papel de la cultura 
Piñero y Juan de Prado constituyó uno de los orígenes del movimiento filosófico más radical y más innovador de la época ${ }^{73}$.

Recibido: 03/11/2019

Aceptado: 11/05/2020

médica hispánica y del ambiente académico de la Castilla barroca; $c f$. Muchnik, Prado, págs. 469-478 y passim. Creeemos que no hay que ir tan lejos como propone la autora.

73 No obstante una visión a veces algo desequilibrada, el enorme valor de los brillantes libros de Jonathan I. Israel acerca del Radical Enlightenment consiste en la revalorización del spinozismo como auténtico inicio de la modernidad intelectual occidental: esta, de hecho, no tenía sus comienzos en la Francia de Voltaire, sino mucho más antes en la Holanda del siglo XvII. 